\title{
IMPLEMENTASI DEEP LEARNING PADA PENGENALAN AKSARA SUNDA MENGGUNAKAN METODE CONVOLUTIONAL NEURAL NETWORK
}

\author{
Shelvi Nur Rahmawati1, *, Eka Wahyu Hidayat², Husni Mubarok ${ }^{3}$ \\ 1,2,3 Prodi Informatika Fakultas Teknik Universitas Siliwangi Jl. Siliwangi No.24 Kota Tasikmalaya 46115 INDONESIA
}

\begin{abstract}
Abstrak
Aksara Sunda merupakan salah satu aksara daerah Indonesia khususnya masyarakat Sunda. Seiring dengan perkembangan teknologi seperti sekarang ini, bahasa daerah pun semakin tergerus dari waktu kewaktu. Aksara Sunda pun mulai terlupakan, bahkan jarang digunakan oleh masyarakat Sunda dalam kehidupan sehari-hari serta kurangnya memahami Bahasa daerahnya sendiri. Oleh karena itu, perlu adanya pelestarian Bahasa daerah yang dikembangkan menyesuaikan perkembangan jaman agar bisa terus dikenal dan dilestarikan, salahsatunya dengan identifikasi aksara Sunda menggunakan metode Convolutional Neural Network (CNN). Convolutional Neural Network (CNN) adalah bagian dari deep learning yang biasanya digunakan dalam pengolahan data gambar. Hasil dari penelitian ini menggunakan optimasi ADAM dengan penggunaan epoch 20, 50, 100 dan 500. Penggunaan epoch 500, learning rate 0.1 merupakan nilai tertinggi dengan akurasi $98.03 \%$. Berdasarkan hasil data training dengan nilai epoch 100 , learning rate 0.001 hasil akurasi sebesar $96.71 \%$ data training dan $92.02 \%$ data testing.
\end{abstract}

Kata Kunci:

Aksara Sunda, Deep

Learning, Convolutional

Neural Network (CNN)

\begin{abstract}
Sundanese script is one of the regional scripts of Indonesia, especially the Sundanese people. Along with the development of technology as it is today, regional languages are increasingly being eroded from time to time. The Sundanese script is starting to be forgotten, it is rarely used by the Sundanese people in their daily life and does not understand their own regional language. Therefore, it is necessary to preserve regional languages which were developed to adapt to the times so that they can be continuously recognized and preserved, one of which is by reading Sundanese script using the Convolutional Neural Network (CNN) method. Convolutional Neural Network (CNN) is a part of deep learning that is usually used in image data processing. The results of this study use ADAM optimization with the use of epochs 20,50, 100 and 500. The use of epoch 500, learning rate 0.1 is the highest value with an accuracy of $98.03 \%$. Based on the results of training data with an epoch value of 100, a learning rate of 0.001 results in an accuracy of $96.71 \%$ of training data and $92.02 \%$ of testing data.
\end{abstract}

\section{Keywords:}

Sundanese script, Deep Learning, Convolutional

Neural Network (CNN)

\section{PENDAHULUAN}

Indonesia merupakan negara yang kaya akan budaya, salahsatu cermin banyaknya budaya di Indonesia adalah banyak sekali bahasa-bahasa yang lahir di Indonesia (Lorentius et al., 2020). Diantara banyaknya bahasa tersebut adalah karakter atau tulisan asli dari berbagai daerah, salahsatunya dari budaya sunda yaitu Aksara sunda. Aksara Sunda salah satu aksara daerah Indonesia yang hasil karya ortografi masyarakat Sunda lewat ekspedisi sejarahnya semenjak 5 abad yang lalu sampai saat ini (Riansyah et al., 2017). Pemeliharaan aksara, bahasa, dan sastra daerah diatur pada Peraturan Daerah (Perda) Nomor 5 Tahun 2003 tentang Pemeliharaan, Aksara, Bahasa, dan Sastra Daerah. Salah satu Aksara Daerah yang dimaksud dalam Perda tersebut adalah Aksara Sunda (Ernawati et al., 2017).

Seiring dengan perkembangan teknologi seperti sekarang ini, bahasa daerah pun semakin tergerus dari waktu kewaktu. Aksara sunda pun mulai terlupakan, bahkan jarang digunakan oleh masyarakat sunda dalam kehidupan sehari-hari serta kurangnya memahami Bahasa daerahnya sendiri. Oleh karena itu, perlu adanya pelestarian Bahasa daerah yang dikembangkan menyesuaikan perkembangan jaman agar bisa terus dikenal dan dilestarikan, salahsatunya dengan identifikasi aksara Sunda menggunakan metode Convolutional Neural Network (CNN). Convolutional Neural Network (CNN) adalah bagian dari deep learning 
yang biasanya digunakan dalam pengolahan data image yang memiliki beberapa lapisan (hidden layer) dan membentuk tumpukkan. Lapisan yang dimaksud merupakan sebuah algoritma yang menghasilkan output ketika mendapatkan perintah klasifikasi input (Nurfita \& Ariyanto, 2018). CNN mempunyai fungsi untuk melakukan filter pada gambar yang memiliki beberapa layer pada setiap prosesnya. Proses tersebut biasa disebut proses training pada citra (Santoso \& Ariyanto, 2018). Penggunaan CNN ini terbukti dapat meningkatkan performa akurasi jika dilihat dari penelitian-penelitian sebelumnya serta berbeda dari algoritma pengolahan citra lainnya, algoritma CNN tidak memerlukan ektraksi fitur tambahan karena sudah terdapat proses ektraksi dan klasifikasi fitur. Proses ektraksi fitur menggunakan proses convolution layer dan subsampling fitur, sedangkan klasifikasi fitur menggunakan proses fully connected layer (Pangestu et al., 2020). Sesuai dengan tujuan penelitian untuk meningkatkan akurasi dan membandingkan hasil dengan menggunakan dataset yang sama dengan penelitian (Amalia et al., 2020) untuk membuktikan metode mana yang akan menghasilkan nilai akurasi yang tinggi dalam pengenalan aksara sunda, maka metode ini sangat cocok untuk meningkatkan akurasi dan klasifikasi. Implementasi metode Convolutional Neural Network (CNN) akan di implementasikan menggunakan MATLAB, sehingga outputnya dapat menampilkan pengenalan aksara Sunda berdasarkan tingkat akurasi sistem.

\section{PENELITIAN TERKAIT}

Beberapa penelitian mengenai aksara sunda sudah banyak dilakukan sebelumnya, diantaranya penelitian (Lestari, 2015) mengenai perancangan pengenal kata dalam aksara sunda menggunakan metode deteksi tepi dan $L V Q$ berbasis pengolahan citra pada android menghasilkan akurasi $61,53 \%$ dengan nilai learning rate 0,01 dan nilai epoch 100 . Penelitian yang dilakukan oleh (Amalia et al., 2020) mengenai pengenalan aksara sunda menggunakan metode Jaringan Saraf Tiruan (JST) backpropagation dan deteksi tepi canny menghasilkan nilai akurasi rata-rata 90\% untuk data latih dan 76.19\% untuk data uji. Pada penelitian ini menyatakan bahwa deteksi tepi canny adalah deteksi tepi terbaik dalam pengolahan kualitas citra karena memiliki Batasan tepi yang jelas.

Selain pengenalan aksara sunda, pengenalan huruf lainnya seperti pada penelitian yang dilakukan oleh (Hara et al., 2016) yang berjudul penggunaan deteksi tepi canny pada sistem pengenalan tulisan tangan aksara lampung berbasis jaringan syaraf tiruan mendapatkan akurasi sebesar 78\%. Penelitian (Prihatiningsih et al., 2019) mengenai analisa performa pengenalan tulisan tangan angka berdasarkan jumlah iterasi menggunakan metode convolutional neural network dengan akurasi yang diperoleh pada iterasi ke 1000 adalah $100,0 \%$ pada training, 98,67\% pada validasi, dan 98,99\% pada testing, untuk mendapatkan nilai akurasi 98,99\% menggunakan latar belakang putih sehingga pixel yang dibandingkan jelas. Pada penelitian ini terdapat kekurangan pada sistemnya karena belum menggunakan Graphical user Interface (GUI).

Berdasarkan beberapa penelitian yang dilakukan sebelumnya, nilai akurasi yang dihasilkan menggunakan metode Convolutional Neural Network pada pengenalan citra mendapatkan akurasi yang cukup baik dalam menangani data yang banyak. Oleh karena itu, penelitian yang akan dilakukan ini mengenai pengenalan aksara sunda menggunakan metode Convolutional Neural Network untuk mengukur performa akurasi. penelitian yang akan dilakukan ini akan membandingkan nilai akurasi dari aksara sunda dengan menggunakan dataset yang sama dari penelitian (Amalia et al., 2020) untuk membuktikan metode mana yang akan menghasilkan nilai akurasi yang tinggi dalam pengenalan aksara sunda, serta melengkapi kekurangan dari penelitian (Prihatiningsih et al., 2019) dengan menggunakan tampilan GUI pada sistemnya. Penelitian ini dikatakan berhasil karena system yang dibuat mampu memecahkan masalah untuk perbandingan akurasi terhadap penelitian mengenai pengenalan aksara Sunda yang menggunakan deteksi tepi canny dan algoritma Jaringan saraf tiruan backpropogation menghasilkan akurasi data training sebesar $90 \%$ dan $76.19 \%$ untuk data uji.

\section{METODE}

Terdapat beberapa tahapan penelitian yang akan dilakukan, ditunjukkan pada Gambar 1 diagram alur berikut: 


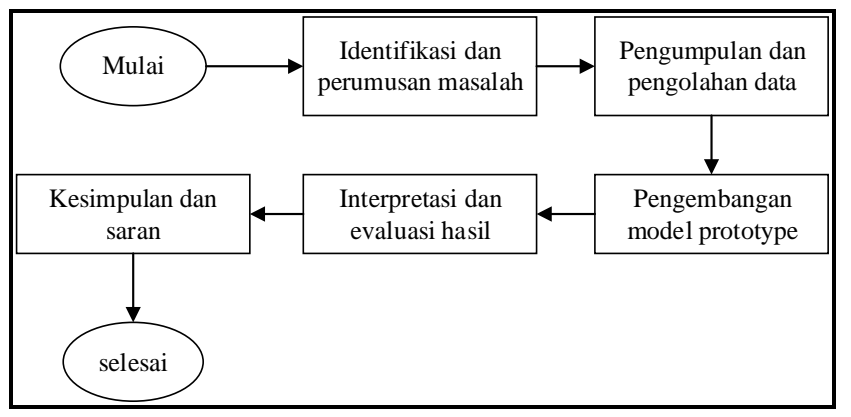

Gambar 1. Diagram alur penelitian

Alur penelitian yang akan dilakukan dijabarkan pada tahapan berikut :

1. Identifikasi dan Perumusan Masalah sebagai proses untuk menjabarkan permasalahan yang akan diteliti. Pemecahan masalah ini menggunakan metode Convolutional Neural Network (CNN) dalam pengenalan aksara sunda untuk mendapatkan nilai akurasi yang lebih baik.

2. Pengumpulan dan pengolahan data yang dilakukan yaitu melakukan studi literatur dengan mempelajari dan memahami teori-teori yang akan digunakan sebagai referensi penelitian.

a. Persiapan Dataset

Data diambil dari penelitian sebelumnya mengenai pengenalan aksara sunda dengan metode JST backpropagation dan deteksi tepi canny. Data diambil dari penelitian tersebut karena untuk membandingkan nilai akurasi dari aksara sunda dengan menggunakan dataset yang sama untuk membuktikan metode mana yang akan menghasilkan nilai akurasi yang tinggi dalam pengenalan aksara sunda. Data yang diperoleh sebanyak 97 citra aksara sunda yang terdiri dari huruf a, i, u, e, eu, é , dan o. Selain itu, untuk dilakukan pengujian terhadap jumlah data training maka ditambahkan dataset dari github sebanyak 847 data aksara sunda swara yang bersumber dari /alifiacrm/aksarasunda-dataset diambil pada 04/23/2021 dan dilakukan preprocessing pada datanya. Total dataset yang digunakan pada penelitian ini adalah 944 data aksara sunda swara yang dimana $80 \%$ untuk citra training dan $20 \%$ untuk citra testing. Sehingga data training yang digunakan sebanyak 756 citra dan data testing 188 . Berikut data yang digunakan perkelasnya, dapat dilihat pada Gambar 2 dan 3.

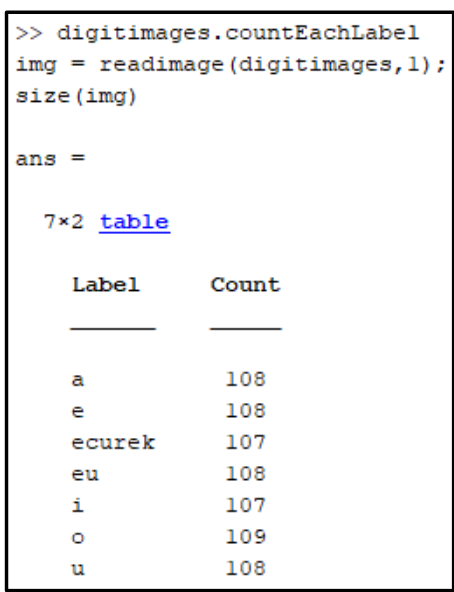

Gambar 2. Data Training

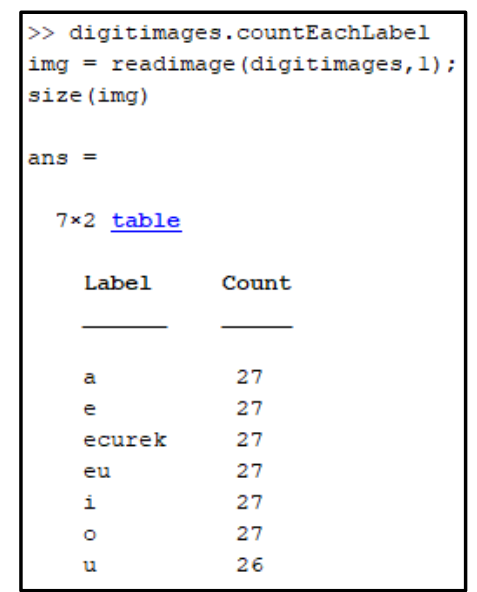

Gambar 3. Data Testing

b. Pre-Processing

Tujuan dilakukannya pre processing untuk meningkatkan kualitas citra agar citra yang diolah mendapatkan hasil yang optimal. Data citra awal berukuran $300 \times 300$ pixel dan 415 x 405 pixel, untuk mempercepat proses dari Convolutional Neural Network (CNN) maka dilakukan proses resize menjadi 64 x 64 pixel yang tujuannya untuk menyamaratakkan citra dan memperkecil ukuran pixel dari citra. Selain proses resize, dilakukan penebalan terhadap pola citranya menggunakan adobe photoshop supaya mendapatkan data-data yang terdeteksi dengan baik. Gambar sebelum dan sesudah preprocessing ditunjukkan pada Gambar 4 dan 5. 


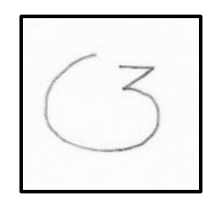

Gambar 4. Citra sebelum processing

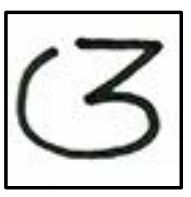

Gambar 5. Citra sesudah processing

3. Pengembangan dan perancangan system menggunakan extreme programming. extreme programming adalah suatu metodologi yang dikenal technical how atau bagaimana suatu tim teknis mengembangkan tahapan perangkat lunak secara efesian dan praktis (Carolina \& Rusman, 2019). Tujuan digunakan pada penelitian ini untuk menyederhanakan berbagai tahapan sehingga lebih fleksibel. Tahapannya meliputi planning, design, coding, dan testing.

a. Planning : tahapan ini untuk mendapatkan gambaran yang jelas mengenai kesuluruhan fungsionalitas dalam system, fitur utama, serta keluaran yang diinginkan.

b. Design : sebagai perancangan system yang terdiri dari desain system serta desain interface.

1) Desain System

Alur system yang akan dibangun menggunakan flowchart ditunjukkan pada Gambar 6 dibawah ini.

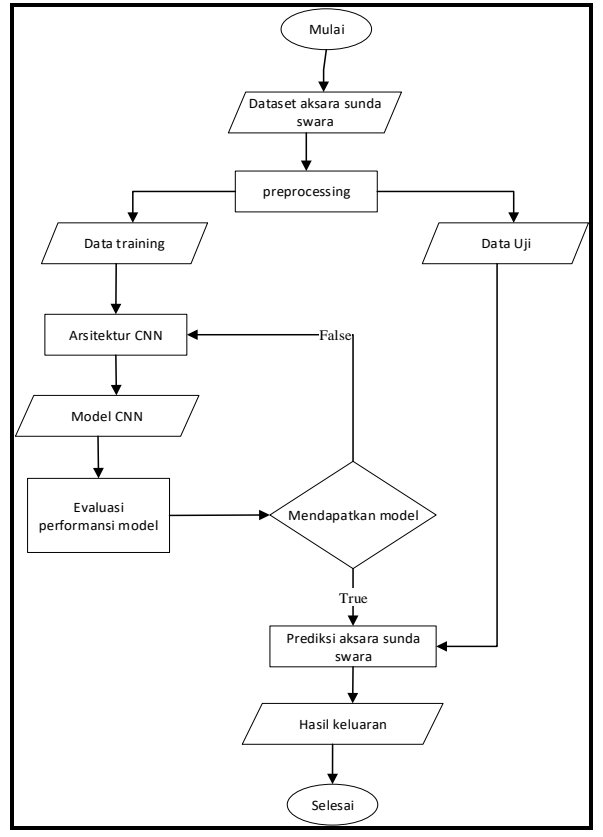

Gambar 6. Alur proses identifikasi aksara Sunda

Penelitian dimulai dari dataset aksara sunda swara yang kemudian dilakukan preprocessing dengan proses hasil resize. Data hasil processing tersebut dibagi menjadi 2 bagian yaitu data training dan data testing. Data training digunakan untuk memberikan pengetahuan pada system, sehingga system telah dilatih dengan pengenalan 7 aksara sunda swara. Sedangkan data uji digunakan untuk menghasilkan keluaran dari proses data training dengan menguji system. Hasil keluaran dari proses ini yaitu menampilkan hasil dari data uji yang telah melalui proses data training, sehingga outputnya dapat menampilkan pengenalan aksara sunda berdasarkan tingkat akurasi system.

2) Desain Interface

Berikut tampilan desain antarmuka system yang dibangun, dapat dilihat pada Gambar 7. 


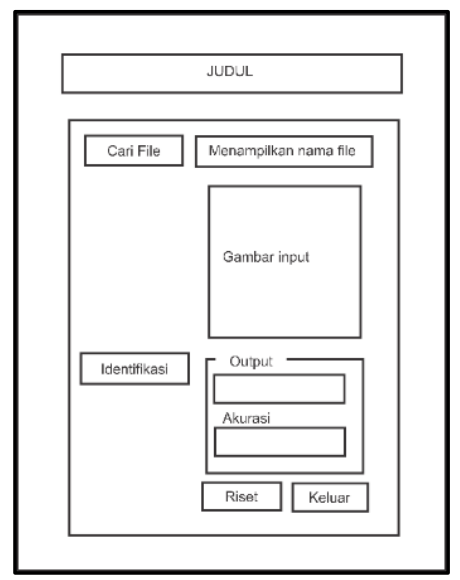

Gambar 7. Interface identifikasi aksara sunda

c. Coding : tahapan ini merupakan tahapan untuk mengimplementasikan semua rancangan planning dan desain ke dalam bentuk program dengan menggunakan matlab dengan mengimplementasikan metode Convolutional Neural Network (CNN).

d. Testing : tahapan ini adalah tahapan pengujian fungsionalitas dari system yang dibangun secara keseluruhan. Pengujian yang dilakukan pada testing :

1) Pengujian black box yang didasarkan pada pengujian tampilan system dan fungsi-fungsi yang ada pada system.

2) Skenario Pengujian

Skenario pengujian dilakukan untuk mengukur tingkat akurasi dari system dalam identifikasi aksara sunda. Ada beberapa tahapan yang dilakukan pada pengujian penelitian ini untuk membandingkan model mana yang terbaik dengan memperhatikan nilai parameternya. Parameter yang dimaksud adalah:

a) Pengaruh penggunaan optimizer SGDM (Stochastic Gradient Descent) dan ADAM (Adaptive Moment Estimation), epoch, dan learning rate terhadap tingkat akurasi system.

Optimizer salahsatu parameter yang digunakan untuk meminimalkan fungsi kerugian agar menghasilkan prediksi yang akurat. Ada beberapa optimizer yang di uji dalam penelitian ini untuk mengetahui optimizer yang sangat berpengaruh terhadap proses penelitian yaitu SGDM dan ADAM. Optimizer SGDM selalu melakukan perbaruan terhadap data yang dilatih, sedangkan optimizer ADAM adalah perbaruan dari optimizer SGDM, untuk menentukan system dalam pembelejaran agar lebih cepat atau lambat maka digunakan suatu nilai learning rate. Learning Rate merupakan suatu parameter yang memperngaruhi terhadap performa model CNN. Terdapat juga epoch yang merupakan banyaknya putaran yang dilakukan pada proses training.

b) Pengaruh ukuran kernel atau filter terhadap tingkat akurasi system.

Kernel merupan matrix untuk mendapatkan fitur dari citra inputan. Kernel yang digunakan pada pengujian ini yaitu 3x3 dan 5x5 untuk mengetahui kernel mana yang menghasilkan akurasi yang tinggi berdasarkan waktu komputasinya.

c) Pengaruh jumlah data training terhadap tingkat akurasi system

Jumlah data yang dilakukan pengujian sebanyak 75 data training - 21 data testing dan 755 data testing - 188 data testing.

4. Interpretasi dan evaluasi hasil

Interpretasi dari hasil dari Implementasi metode Convolutional Neural Network (CNN) dalam pengenalan aksara sunda menggunakan matlab dan didapatkan nilai akurasinya, yang selanjutnya dilakukan pengujian dan evaluasi apakah sesuai atau tidak dan dilakukan perhitungan akurasinya. Proses perhitungan akurasi menggunakan persamaan :

$$
\text { Akurasi }=\frac{\text { Jumlah data benar }}{\text { Jumlah data } u j i} \times 100 \%
$$




\section{Arsitektur Jaringan Convolutional Neural Network (CNN)}

Data citra awal berukuran 300 × 300 pixel dan 415 × 405 pixel. Karena ukuran citra tersebut terlalu besar, maka untuk mempercepat proses dari Convolutional Neural Network (CNN) dan keterbatasan hardware maka peneliti menggunakan input gambar ukurannya 64 x 64 pixel dengan ukuran lebih kecil daripada resolusi gambar standar. Berikut model arsitektur yang digunakan untuk proses training ditunjukkan pada Tabel 1 dibawah ini.

Tabel 1. Arsitektur model CNN

\begin{tabular}{cc}
\hline Jenis Jaringan & Bentuk dan parameter \\
\hline Image Input & $64 \times 64 \times 3$ \\
Conv1+ Relu & 32 filter $(3 \times 3)$ \\
maxpooling & $(2 \times 2)$ \\
Conv2+ Relu & 32 filter $(3 \times 3)$ \\
maxpooling & $(2 \times 2)$ \\
Conv3+ Relu & 64 filter $(3 \times 3)$ \\
maxpooling & $(2 \times 2)$ \\
Conv4+ Relu & 128 filter $(3 \times 3)$ \\
Dropout & $10 \%$ \\
flatten & 7 (n-class) \\
Fully connected layer & \\
softmax & \\
\hline
\end{tabular}

Arsitektur jaringan pada gambar Tabel 1 dipaparkan sebagai berikut:

1. Input gambar yang digunakan pada penelitian ini adalah 64x64 pixel. Ukuran citra yang digunakan ini memiliki channel image RGB yang di inisialisasikan dengan angka 3.

2. Inputan citra melalui tahapan konvolusi untuk mendeteksi pola yang tujuannya untuk mengektraksi ciri dari citra input. Konvolusi kernel menggunakan ukuran $3 \times 3$ dan $5 \times 5$ tujuannya untuk membandingkan perfoma akurasi berdasarkan ukuran kernel. Hasil operasi konvolusi ini dihasilkan dari perkalian dua fungsi yang dimana akan menghasilkan nilai matrik baru. Konvolusi proses pertama di jumlahkan dan dilakukan pergeseran (stride). Hasul konvolusi ditambahkan aktivasi fungsi RELU (Retrified Linear Unit) yang bertujuan untuk mengubah nilai negative menjadi 0 dan mempertahankan nilai positif.

3. Proses pooling digunakan untuk melakukan pengurangan ukuran citra agar feature learningnya semakin cepat. pada penelitian ini menggunakan max-pooling dengan kernel pooling 2x2 karena metode ini merupakan metode terbaik dalam proses pooling. Cara kerja max-pooling adalah mengambil nilai maksimum.

4. Proses selanjutnya yaitu mengulangi proses 2 dan 3, tetapi yang membedakannya hanya pada tampilan output yang dihasilkan.

5. Proses dropout adalah proses memilih beberapa neuron yang tidak digunakan selama proses training, dan neuron ini akan dibuang secara acak agar tidak mengakibatkan overfitting pada proses training.

6. Flatten ini mengubah nilai yang dihasilkan oleh konvolusi pooling menjadi sebuah vector agar bisa digunakan sebagai inputan dari fully connected layer. Fully connected layer digunakan untuk klasifikasi fitur dari semua neuron, pada penelitian ini menggunakan 7 fully connected layer. Angka 7 ini dihasilkan dari jumlah kategori dataset yang digunakan yaitu a, i, u, e, eu, ^e, dan o.

7. Fungsi terakhir adalah fungsi aktivasi softmax. Fungsi ini digunakan untuk metode klasifikasi multikelas. Berikut salahsatu hasil output dari proses identifikasi yang ditampilan pada Gambar 8. 


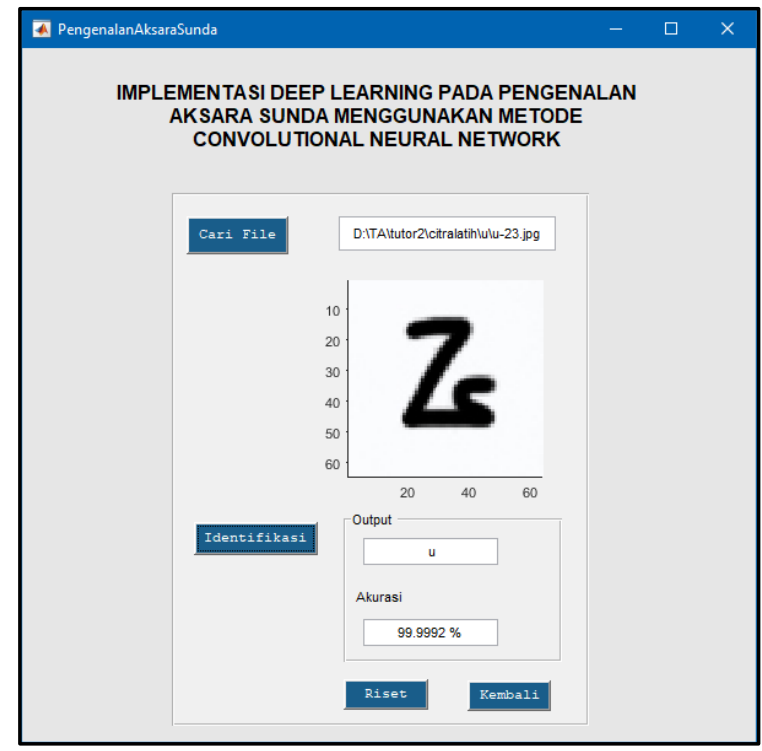

Gambar 8. Ujicoba identifikasi citra sunda

\section{HASIL DAN PEMBAHASAN}

\section{A. Skenario Pengujian}

Ada beberapa tahapan yang dilakukan pada pengujian penelitian ini untuk membandingkan model mana yang terbaik dengan memperhatikan nilai parameternya. Parameter yang dimaksud adalah:

a) Pengaruh penggunaan optimizer, learning rate, dan epoch terhadap tingkat akurasi system

Optimizer yang diuji dalam penelitian ini yaitu ADAM dan SGDM untuk membandingkan parameter optimasi yang menghasilkan tingkat akurasi terbaik, serta penggunan learning rate dan epoch untuk mengetahui parameter-parameter yang mana yang sangat berpengaruh terhadap model.

Hasil ujicoba optimasi ADAM (Adaptive Moment Estimation)

Tabel 2. Optimizer ADAM

\begin{tabular}{ccccc}
\hline Epoch & $\begin{array}{c}\text { Learning } \\
\text { rate }\end{array}$ & $\begin{array}{c}\text { Accuracy } \\
\text { Validation }\end{array}$ & $\begin{array}{c}\text { Loss } \\
\text { Validation }\end{array}$ & $\begin{array}{c}\text { Time } \\
\text { (hour.minute.seconds) }\end{array}$ \\
\hline \multirow{2}{*}{20} & 0.1 & $75.00 \%$ & 0.7481 & 02.06 \\
\cline { 2 - 5 } Epoch & 0.01 & $88.16 \%$ & 0.4433 & 02.14 \\
& $\begin{array}{c}\text { Learning } \\
\text { rate }\end{array}$ & $\begin{array}{c}\text { Accuracy } \\
\text { Validation }\end{array}$ & $\begin{array}{c}\text { Loss } \\
\text { Validation }\end{array}$ & $\begin{array}{c}\text { Time } \\
\text { (hour.minute.seconds) }\end{array}$ \\
\hline \multirow{5}{*}{50} & 0.001 & $92.76 \%$ & 0.1465 & 02.08 \\
\cline { 2 - 5 } & 0.0001 & $90.13 \%$ & 0.3968 & 01.58 \\
\cline { 2 - 5 } & 0.1 & $96.05 \%$ & 0.1909 & 03.52 \\
\cline { 2 - 5 } & 0.01 & $90.79 \%$ & 0.5351 & 04.38 \\
\hline 100 & 0.001 & $96.05 \%$ & 0.1196 & 04.47 \\
\cline { 2 - 5 } & 0.0001 & $88.82 \%$ & 0.3519 & 04.50 \\
\cline { 2 - 5 } & 0.1 & $86.18 \%$ & 1.0944 & 09.18 \\
\cline { 2 - 5 } & 0.01 & $88.82 \%$ & 0.4572 & 09.30 \\
\hline 500 & 0.001 & $96.71 \%$ & 0.1221 & 09.24 \\
& 0.0001 & $90.79 \%$ & 0.3318 & 09.30 \\
\cline { 2 - 5 } & 0.1 & $98.03 \%$ & 0.0540 & 44.45 \\
\cline { 2 - 5 } & 0.01 & $90.13 \%$ & 0.3668 & 46.57 \\
\cline { 2 - 5 } & 0.001 & 96.71 & 0.1238 & 52.51 \\
\hline
\end{tabular}

Berdasarkan Tabel 2 menunjukkan bahwa nilai learning rate standar optimizer ADAM terbukti yaitu 0.001 dengan nilai akurasi tertinggi terletak di learning rate 0.001 dengan nilai epoch yang berbeda. Nilai epoch 20 untuk akurasi tertinggi mencapai $92.76 \%$ dengan nilai learning rate 0.001 . Nilai epoch 50 untuk akurasi tertinggi $96.05 \%$ dengan nilai learning rate 0.1. Epoch 100 mendapatkan akurasi tertinggi $96.71 \%$ dengan menggunakan learning rate 0.001 . Penggunaan epoch 500 nilai akurasi tertinggi $98.03 \%$ dengan 
learning rate 0.1. Dapat disimpulkan bahwa nilai epoch dan learning rate sangat mempengaruhi tingkat akurasi, semakin besar jumlah epoch maka akurasi yang didapatkan semakin tinggi dan membutuhkan waktu yang banyak, sedangkan jika semakin besar jumlah learning rate maka semakin bagus akurasinya. Selain itu, semakin banyak ataupun sedikit jumlah learning rate yang digunakan pada model, belum tentu menambah waktu komputasi.

Hasil ujicoba optimasi SGDM (Stochastic Gradient Descent)

Tabel 3. Optimizer SGDM

\begin{tabular}{ccccc}
\hline Epoch & $\begin{array}{c}\text { Learning } \\
\text { rate }\end{array}$ & $\begin{array}{c}\text { Accuracy } \\
\text { Validation }\end{array}$ & $\begin{array}{c}\text { Loss } \\
\text { Validation }\end{array}$ & $\begin{array}{c}\text { Time } \\
\text { (hour.minute.seconds) }\end{array}$ \\
\hline 20 & 0.1 & $86.18 \%$ & 0.4366 & 02.13 \\
& 0.01 & $90.79 \%$ & 0.3162 & 02.16 \\
& 0.001 & $89.47 \%$ & 0.3644 & 02.06 \\
& 0.0001 & $67.76 \%$ & 0.9457 & 02.13 \\
50 & 0.1 & $88.82 \%$. & 0.5852 & 05.23 \\
& 0.01 & $92.76 \%$ & 0.2521 & 05.14 \\
& 0.001 & $90.79 \%$. & 0.2502 & 05.16 \\
100 & 0.0001 & $77.63 \%$. & 0.6481 & 05.14 \\
& 0.1 & $88.16 \%$ & 0.4254 & 10.15 \\
& 0.01 & $94.08 \%$. & 0.3082 & 09.52 \\
500 & 0.001 & $88.82 \%$ & 29.73 & 10.01 \\
& 0.0001 & $85.53 \%$ & 0.4912 & 09.10 \\
& 0.1 & $98.03 \%$ & 0.1043 & 45.16 \\
& 0.01 & 95.39 & 0.2142 & 01.14 .21 \\
& 0.001 & 94.74 & 0.1811 & 51.02 \\
& 0.0001 & 88.16 & 0.3 .64 & 52.34 \\
\hline
\end{tabular}

Berdasarkan Tabel 3 hasil pengujian penggunaan nilai epoch dan learning rate didapatkan pengujian paling tinggi yaitu penggunaan nilai epoch 500 dan learning rate 0.1 dengan akurasi $98.03 \%$, tetapi pada proses trainingnya membutuhkan waktu yang lama yaitu 45 menit 16 detik. Jika diambil nilai epoch 100 maka untuk optimasi SGDM mendapatkan nilai tertinggi 94.08\% dengan learning rate standar yaitu 0.01 dan untuk optimasi ADAM mendapatkan nilai tertinggi $96.71 \%$ dengan nilai learning rate standar dari ADAM yaitu 0.001. Maka pada penelitian ini akan menggunakan optimasi ADAM, epoch 100 dan learning rate 0.001 untuk pengujian selanjutnya.

b) Pengaruh ukuran kernel atau filter terhadap tingkat akurasi system

Penelitian ini menggunaan ukuran kernel 3x3 dan 5x5 untuk mengetahui pengaruh kernel terhadap tingkat akurasi system. Berikut hasil ujicoba penggunaan kernel yang disajikan dalam Tabel 4.

Tabel 4. Perbandingan kernel 3x3 dan 5x5

\begin{tabular}{cccc}
\hline Ukuran kernel & $\begin{array}{c}\text { Accuracy } \\
\text { Validation }\end{array}$ & $\begin{array}{c}\text { Loss } \\
\text { Validation }\end{array}$ & $\begin{array}{c}\text { Time } \\
\text { (minute.seconds) }\end{array}$ \\
\hline $3 \times 3$ & $96.71 \%$ & 0.1221. & 09.24 \\
$5 \times 5$ & $96.71 \%$ & 0.1240 & 13.50 \\
\hline
\end{tabular}

Berdasarkan Tabel 4 hasil pengujian penggunaan kernel 3x3 dan 5x5 dengan menggunakan nilai epoch 100 dan learning rate 0.001 mendapatkan hasil akurasi keduanya $96.71 \%$ dengan proses yang stabil, untuk hasil loss pun tidak berbeda jauh. Tetapi, penggunaan kernel 3x3 menggunakan waktu komputasi yang lebih cepat dibandingkan penggunaan kernel $5 \times 5$.

c) Pengaruh jumlah data training dan testing terhadap tingkat akurasi system

1) Jumlah data training dari penelitian (Amalia, Hidayat, \& Aldya, 2020) dengan jumlah 75 aksara Sunda swara. Proses Training dapat dilihat pada Gambar 9 dan 10 dibawah ini . 


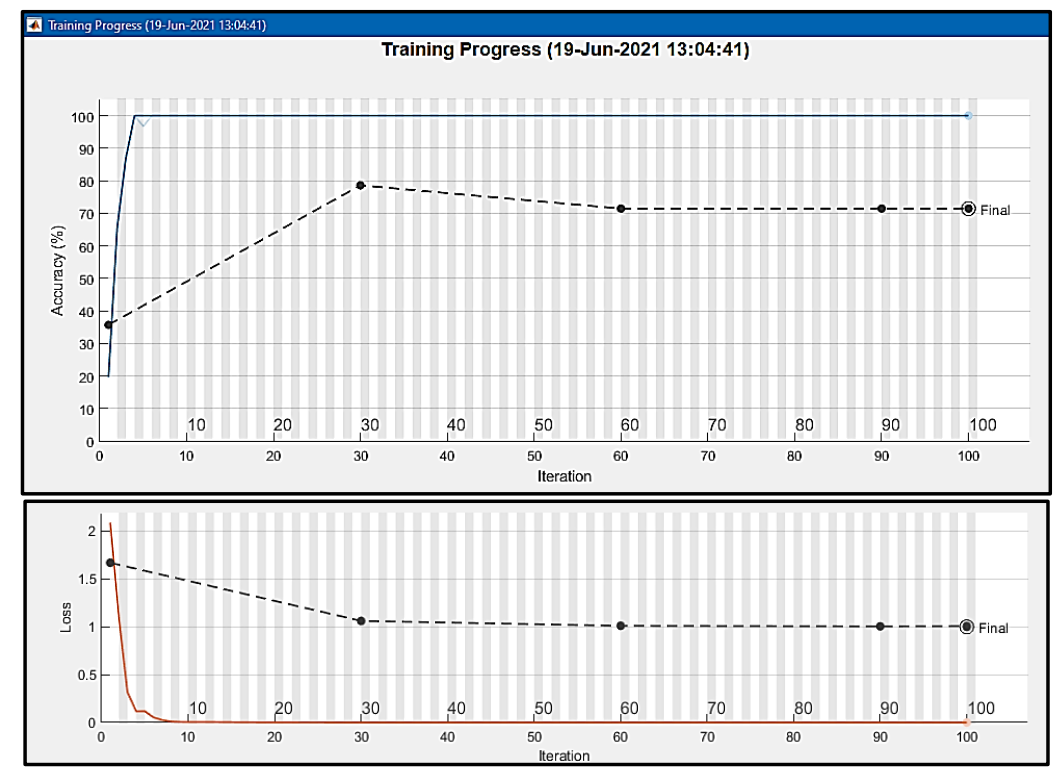

Gambar 9. Grafik accuracy dan loss 75 citra epoch 100 learning rate 0.001

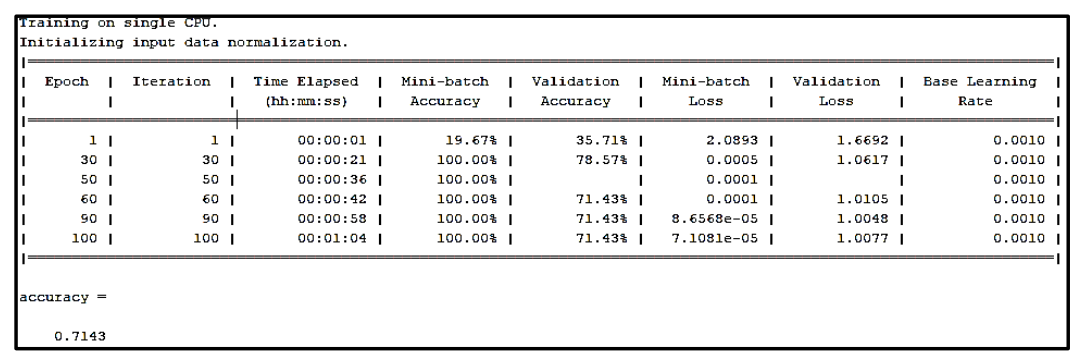

Gambar 10. Hasil training dan validation pengujian 75 citra

Berdasarkan Gambar 7 dan 8 hasil training didapatkan hasi pengujian dengan jumlah data training 75 huruf sebesar $71.43 \%$ dengan nilai epoch 100, learning rate 0.001 , dan optimizer ADAM. Hasil loss yang didapat tinggi pada epoch ke 1 sampai 30 dan menurun dari epoch ke 30 sampai ke akhir. Nilai loss ini sangat mempengaruhi terhadap akurasi yang didapatkan.

2) Jumlah data testing dari penelitian (Amalia, Hidayat, \& Aldya, 2020) yang telah dilakukan preprocessing citranya dengan jumlah 21 aksara Sunda swara. Berikut hasil ujicoba data testing dapat dilihat pada Tabel 5 dibawah ini :

Tabel 5. Uji coba data testing dengan jumlah 21 aksara swara

\begin{tabular}{cccccccl}
\hline No & $\begin{array}{c}\text { Input } \\
\text { huruf }\end{array}$ & \multicolumn{3}{c}{ Output } & terdeteksi & $\begin{array}{c}\text { Gagal } \\
\text { terdeteksi }\end{array}$ & Akurasi \\
\cline { 3 - 5 } & $\mathrm{a}$ & $\wedge \mathrm{e}$ & $\mathrm{a}$ & $\mathrm{e}$ & 2 & 1 & $66.67 \%$ \\
2 & $\mathrm{i}$ & $\mathrm{i}$ & $\mathrm{i}$ & $\mathrm{i}$ & 3 & 0 & $100 \%$ \\
3 & $\mathrm{u}$ & $\mathrm{u}$ & $\mathrm{u}$ & $\mathrm{e}$ & 2 & 1 & $66.67 \%$ \\
4 & $\mathrm{e}$ & $\mathrm{e}$ & $\mathrm{e}$ & $\mathrm{e}$ & 3 & 0 & $100 \%$ \\
5 & $\mathrm{eu}$ & $\mathrm{eu}$ & $\mathrm{eu}$ & $\mathrm{eu}$ & 3 & 0 & $100 \%$ \\
6 & $\wedge \mathrm{e}$ & $\wedge \mathrm{e}$ & $\wedge \mathrm{e}$ & $\mathrm{a}$ & 2 & 1 & $66.67 \%$ \\
7 & $\mathrm{o}$ & $\mathrm{o}$ & $\mathrm{o}$ & $\mathrm{o}$ & 3 & 0 & $100 \%$ \\
Jumlah & & & & & 18 & 3 & 21 \\
& & & & & & & \\
\hline
\end{tabular}

Jumlah data testing dari 21 huruf yang terdeteksi 18 huruf dan 3 gagal terdeteksi sehingga menghasilkan rata-rata jumlah akurasi sebesar $85.71 \%$ yang didapatkan dari rumus persamaan : 


$$
\begin{aligned}
\text { Akurasi } & =\frac{\text { Jumlah data benar }}{\text { Jumlah data uji }} \times 100 \% \\
& =\frac{18}{21} \times 100 \% \\
& =\mathbf{8 5 . 7 1} \%
\end{aligned}
$$

Hasil akurasi testing dengan gambar input baru yang diperoleh dari ukuran gambar input 64x64 piksel sudah menunjukkan hasil yang baik karena dengan data training yang sedikit.

3) Jumlah data training keseluruhan pada penelitian ini sebanyak 756 huruf.

Hasil akurasi yang didapat dengan menggunakan 756 citra huruf pada data dengan menggunakan epoch 100 dan learning rate 0.001 dengan model optimizer ADAM mendapatkan akurasi sebesar $96.71 \%$ berikut tampilan proses data training yang ditampilkan pada Gambar 11, 12 dan 13 dibawah ini :

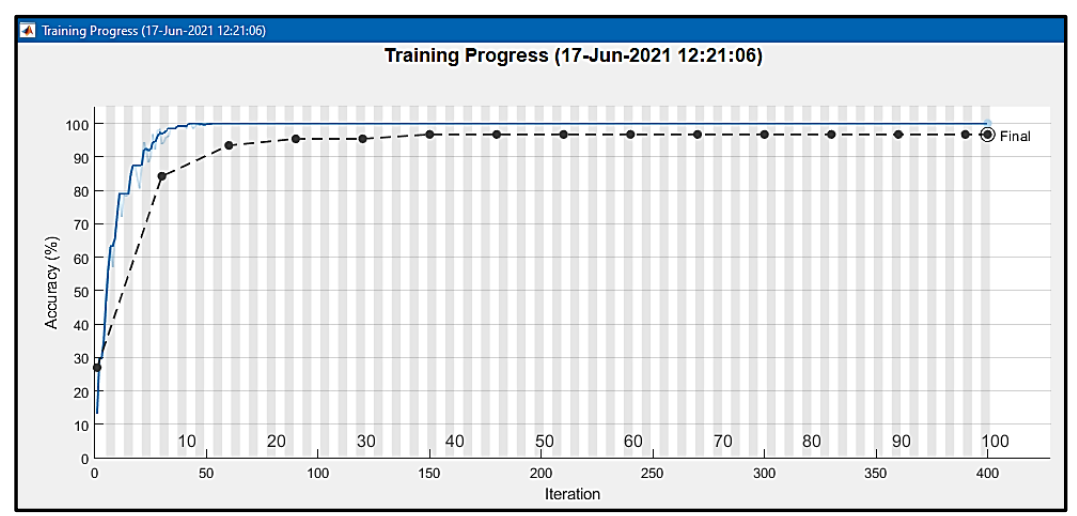

Gambar 11. Grafik accuracy 756 citra epoch 100 learning rate 0.001

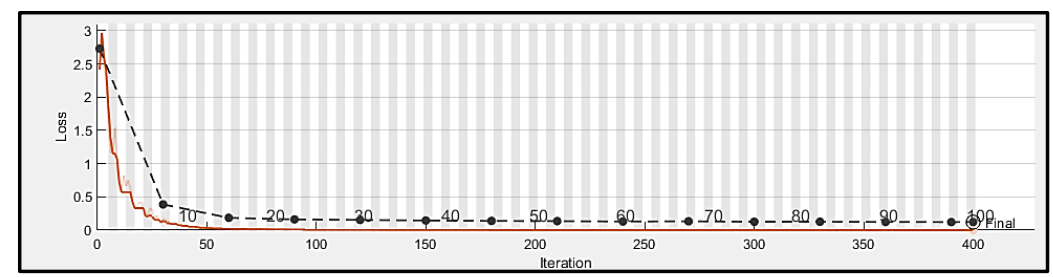

Gambar 12. Grafik loss 756 citra epoch 100 learning rate 0.001

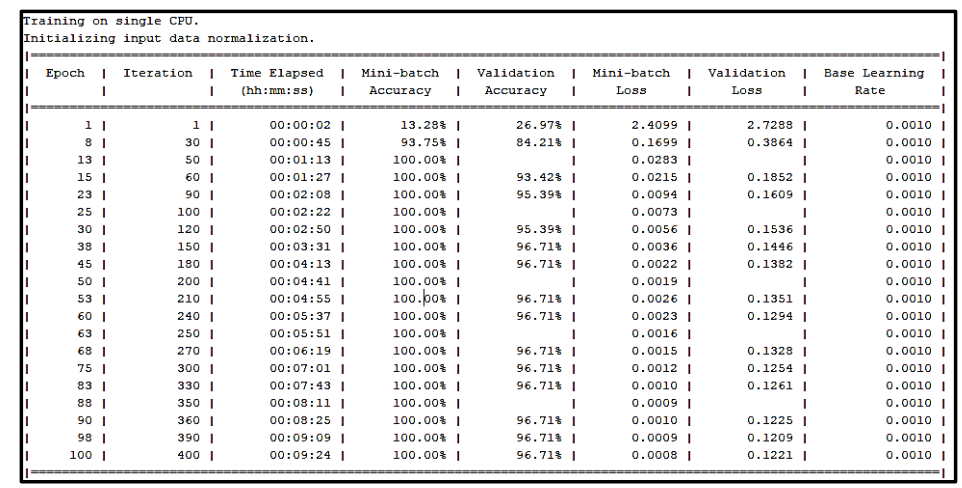

Gambar 13. Hasil training dan validation pengujian 756 citra 
4) Ujicoba data testing pada penelitian ini sebanyak 188 huruf.

Pengujian testing ini menggunakan data citra baru yang sebelumnya belum digunakan pada data training, untuk pengujian data testing ini berjumlah 188 huruf. Berikut hasil ujicoba data testing dapat dilihat pada Tabel 6 dibawah ini :

Tabel 6. Pengujian data testing pada citra

\begin{tabular}{cccc}
\hline Label & Jumlah data & Berhasil Terdeteksi & Gagal Terdeteksi \\
\hline $\mathrm{a}$ & 27 & 17 & 10 \\
$\mathrm{i}$ & 27 & 27 & 0 \\
$\mathrm{u}$ & 26 & 26 & 0 \\
$\mathrm{e}$ & 27 & 27 & 0 \\
$\wedge \mathrm{e}$ & 27 & 24 & 3 \\
$\mathrm{eu}$ & 27 & 26 & 1 \\
$\mathrm{o}$ & 27 & 26 & 1 \\
Jumlah & 188 & 173 & 15 \\
\hline
\end{tabular}

Dari 188 jumlah data testing, data yang behasil terdeteksi pada saat pengujian citra yaitu 173 terdeteksi dan 15 citra gagal terdeteksi. Data citra yang tidak terdeteksi ini disebabkan oleh data citra yang hampir menyerupai pola citra lainnya. Seperti huruf a kebanyakan data citra yang gagal terdeteksi ini karena menyerupai huruf dari ${ }^{\wedge} \mathrm{e}$, huruf ${ }^{\wedge} \mathrm{e}$ yang tidak terdeteksi ini terdeteksi sebagai huruf a, dan huruf dari o terdeteksi menyerupai huruf $u$.

Perhitungan akurasi dari data testing didapatkan dari rumus persamaan :

$$
\begin{aligned}
\text { Akurasi } & =\frac{\text { Jumlah data benar }}{\text { Jumlah data uji }} \times 100 \% \\
& =\frac{173}{188} \times 100 \%=\mathbf{9 2 . 0 2} \%
\end{aligned}
$$

Jadi, akurasi yang dihasilkan model dengan input gambar 64x64 pixel jumlah data testing 188 didapatkan nilai akurasi testing sebesar $92.02 \%$.

Berikut tabel hasil perbandingan terhadap jumlah data training yang digunakan :

\begin{tabular}{|c|c|c|c|}
\hline Training - Testing & Accuracy validation & Loss Validation & Accuracy testing \\
\hline $75-21$ & $71.43 \%$ & 1.0077 & $85.71 \%$ \\
\hline - 188 & $96.71 \%$ & 0.0008 & $92.02 \%$ \\
\hline
\end{tabular}

Tabel 7. Hasil perbandingan penggunaan data

Dapat dilihat pada Tabel 7 bahwa semakin banyak jumlah data training yang digunakan, maka tingkat akurasi yang dihasilkan akan semakin tinggi. Hal ini disebabkan oleh system yang banyak memahami pola dari gambar yang dimasukkan, sehingga akurasi yang dihasilkan dalam proses identifikasi semakin akurat.

\section{B. Interpretasi dan Evaluasi Hasil}

Penelitian ini dikatakan berhasil karena system yang dibuat mampu memecahkan masalah untuk perbandingan akurasi terhadap penelitian dari (Amalia et al., 2020) mengenai pengenalan aksara Sunda yang menggunakan deteksi tepi canny dan algoritma Jaringan saraf tiruan backpropogation menghasilkan akurasi data training sebesar $90 \%$ dan $76.19 \%$ untuk data uji. Penggunaan metode CNN pada penelitian ini menggunakan dataset yang sama memiliki tingkat akurasi training sebesar $71.43 \%$ lebih kecil dibanding yang sebelumnya yaitu $90 \%$ tetapi untuk data testing lebih besar yaitu $85.71 \%$. Sedangkan untuk tambahan dari data training yang menggunakan 755 data training yang digunakan pada penelitian ini mendapatkan nilai akurasi data training $96.71 \%$ dengan data uji sebesar $92.02 \%$. Berikut informasi perbandingan hasil klasifikasi (confusion matrik) yang dihasilkan dari proses validation pada data training yang digunakan oleh system, dapat dilihat pada Gambar 14 dibawah ini. 


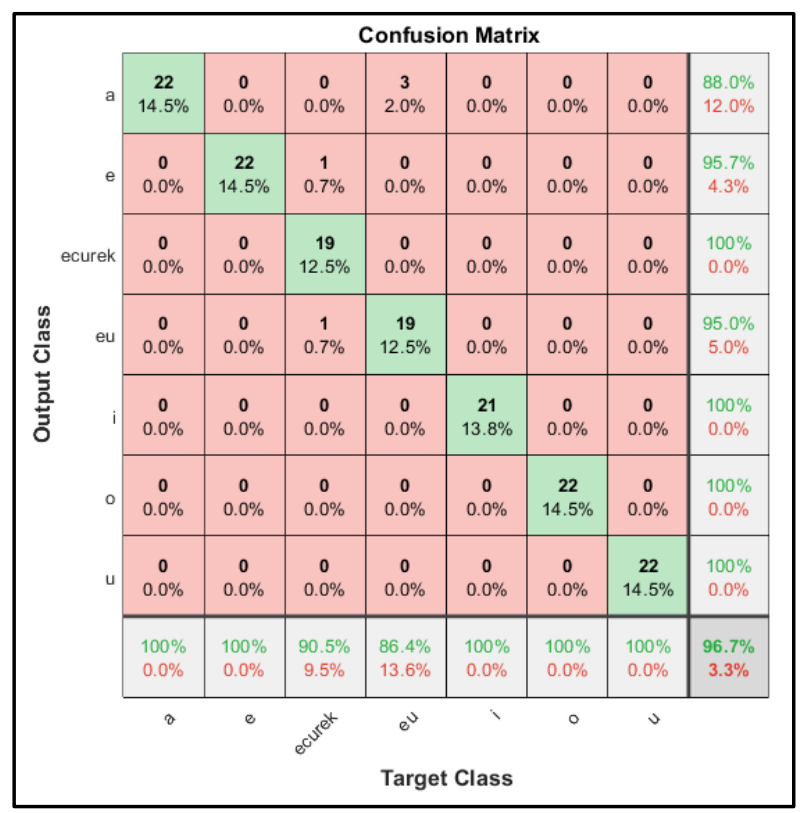

Gambar 14. Confusion Matrix

Dari Gambar 14 menunjukkan jumlah dan presentase klasifikasi yang ditraining oleh jaringan. Baris sesuai kelas yang diprediksi ditunjukkan pada kelas output dan kolom kelas ditunjukkan pada kelas target. Misal diambil huruf a, hasil klasifikasi huruf a mendapatkan 22 benar diklasifikasikan benar sebagai huruf a yaitu $14.5 \%$ dari 25 data, dan 3 salah diklasifikasikan sebesar 2.0\%. Prediksi keseluruhan huruf a 88.0\% benar dan $12.0 \%$ salah. Kolom kanan pada plot menunjukkan presentase prediksi setiap kelas yang di prediksi benar dan salah atau sering disebut presisi dan plot bawah menunjukkan hasil presentase dari tiap kelas yang diklasifikasikan dengan benar dan salah atau sering disebut recall. Secara keseluurhan mendapatkan akurasi $96.7 \%$ prediksi benar dan salah $3.3 \%$.

Jika dilihat dari hasil yang didapatkan dari penelitian yang dilakukan dengan penelitian sebelumnya, penggunaan CNN ini dipengaruhi oleh penggunaan jumlah data training. Semakin banyak jumlah data training yang digunakan, maka tingkat akurasi yang dihasilkan akan semakin tinggi. Hal ini disebabkan oleh model yang dilatih banyak memahami pola dari gambar yang dimasukkan, sehingga akurasi yang dihasilkan dalam proses identifikasi semakin akurat. Pada penelitian ini akurasi yang di dapat lebih tinggi menggunakan dataset data training 755 dan data testing 188 karena penggunaan algoritma CNN sangat cocok untuk memproses data banyak serta mampu meningkatkan akurasi dalam pengenalan citranya. Sedangkan untuk penelitian sebelumnya disebabkan oleh data citra yang digunakan dalam pengujian mempengaruhi nilai akurasi, semakin baik dan jelas tulisan maka aksara dapat terdeteksi sesuai dengan polanya.

\section{SIMPULAN DAN SARAN}

Berdasarkan penelitian yang telah dilakukan mengenai Implementasi deep learning pada pengenalan aksara Sunda, diperoleh kesimpulan hasil penelitian dengan menggunakan epoch 20, 50, 100 dan 500, didapatkan penggunaan epoch tertinggi 500 dengan akurasi sebesar $98.03 \%$ learning rate 0.1 dan optimasi ADAM. Pengujian penggunaan kernel 3x3 dan 5x5 dengan menggunakan nilai epoch 100 dan learning rate 0.001 mendapatkan hasil akurasi $96.71 \%$ pada penggunaan kernel 3x3 berdasarkan waktu prosesnya. Berdasarkan perbandingan dengan peneliti sebelumnya pada penelitian Amalia, dkk (2020) penelitian mengenai pengenalan aksara Sunda yang menggunakan deteksi tepi canny dan algoritma Jaringan saraf tiruan backpropogation menghasilkan akurasi data training sebesar 90\% dengan jumlah 70 data aksara Sunda, dan 76.19\% untuk data uji. Penggunaan metode CNN pada penelitian menggunakan dataset yang sama memiliki tingkat akurasi training sebesar $71.43 \%$ lebih kecil dibanding yang sebelumnya yaitu $90 \%$ tetapi untuk data testing lebih besar yaitu 85.71\%. Sedangkan untuk tambahan dari data training yang menggunakan 755 data training yang digunakan pada penelitian ini mendapatkan nilai akurasi data training 96.71\% dengan data uji sebesar 92.02\%. Semakin banyak jumlah data training yang digunakan, maka tingkat akurasi yang dihasilkan akan semakin tinggi. Hal ini disebabkan oleh model yang dilatih banyak memahami pola dari gambar yang dimasukkan, sehingga akurasi yang dihasilkan dalam proses identifikasi semakin akurat. 
Adapun saran yang dari penulis untuk pengembangan penelitian selanjutnya yaitu menambah parameter perbandingan ukuran gambar yang digunakan lebih besar ukuran pixelnya untuk mengetahui hasil penggunaan parameter yang terbaik, menggunakan citra aksara Sunda yang lebih lengkap, menambah atau mengubah metode dengan metode lain untuk dijadikan perbandingan hasil akurasi dengan hasil testing yang lebih baik, dan mengimplementasikan gambar yang berhasil di identifikasi dengan menggunakan perangkat keras seperti webcam.

\section{Ucapan Terima Kasih}

Penyusunan Tugas Akhir ini dapat penulis selesaikan diwaktu yang tepat berkat kehadirat Allah SWT yang telah memberikan kekuatan dan kesabaran serta memberikan jalan menuju kemudahan sehingga penulis dapat menyelesaikan laporan Tugas Akhir dan tentunya tidak lepas dari bantuan berbagai pihak. Pada kesempatan ini penulis mengucapkan terimakasih sebesar-besarnya kepada Bapak Eka Wahyu Hidayat S.T.,M.T. selaku Dosen pembimbing I dan Bapak Husni Mubarok, STP., MT selaku Dosen pembimbing II yang senantiasa memberikan bimbingan, arahan, meluangkan waktu, serta pikirannya sehingga Tugas Akhir ini dapat terselesaikan. Kedua orang tua, adik, serta keluarga besar yang selalu memberikan dukungan dan doanya sehingga Tugas Akhir ini dapat terselesaikan. Rekan-rekan mahasiswa Informatika seperjuangan khususnya 2017 serta semua pihak lainnya yang tidak dapat disebutkan satu persatu. Semoga Allah SWT memberikan balasan yang pantas atas kebaikannya. Terima kasih atas bantuannya dan semoga laporan ini memberikan manfaat bagi penulis maupun pembaca.

\section{Daftar Pustaka}

Amalia, N., Hidayat, E. W., \& Aldya, A. P. (2020). Pengenalan Aksara Sunda Menggunakan Metode Jaringan Saraf Tiruan Backpropagation Dan Deteksi Tepi Canny. CESS (Journal of Computer Engineering, System and Science), 5(1), 19. https://doi.org/10.24114/cess.v5i1.14839

Carolina, I., \& Rusman, A. (2019). Penerapan Extreme Programming Pada Sistem Informasi Penjualan Pakaian Berbasis Web (Studi Kasus Toko ST Jaya). INOVTEK Polbeng - Seri Informatika, 4(2), 157. https://doi.org/10.35314/isi.v4i2.1043

Ernawati, R. S., Hidayat, E. W., \& Rahmatulloh, A. (2017). Implementasi Teknologi Augmented Reality Sebagai Media Pengenalan Aksara Sunda Berbasis Android. Jurnal Teknik Informatika Dan Sistem Informasi, 3(3), 512-523. https://doi.org/10.28932/jutisi.v3i3.671

Hara, E., Fitriawan, H., \& Mulyani, Y. (2016). Penggunaan Deteksi Tepi ( Canny) pada Sistem Pengenalan Tulisan Tangan Aksara Lampung Berbasis Jaringan Syaraf Tiruan. ELECTRICIAN - Jurnal Rekayasa Dan Teknologi Elektro, 10(3), 8.

Lestari, D. D. (2015). ANDROID DESIGN OF SUNDANESE SCRIPT WORDS RECOGNATION USING EDGE DETECTION AND LVQ METHOD BASED ON IMAGE PROCESSING ON ANDROID.

Lorentius, C. A., Adipranata, R., \& Tjondrowiguno, A. (2020). Pengenalan Aksara Jawa dengan Menggunakan Metode Convolutional Neural Network. E-Proceeding of Engineering, 7(1), 2558-2567.

Nurfita, R. D., \& Ariyanto, G. (2018). Implementasi Deep Learning Berbasis Tensorflow Untuk Pengenalan Sidik Jari. Emitor: Jurnal Teknik Elektro, 18(01), 22-27. https://doi.org/10.23917/emitor.v18i01.6236

Pangestu, R. A., Rahmat, B., \& Anggraeny, F. T. (2020). Implementasi Algoritma CNN untuk Klasifikasi Citra Lahan dan Perhitungan Luas. Informatika Dan Sistem Informasi, 1(1), 166-174.

Prihatiningsih, S., M, N. S., Andriani, F., \& Nugraha, N. (2019). Analisa Performa Pengenalan Tulisan Tangan Angka Berdasarkan Jumlah Iterasi Menggunakan Metode Convolutional Neural Network. Jurnal Ilmiah Teknologi Dan Rekayasa, 24(1), 58-66. https://doi.org/10.35760/tr.2019.v24i1.1934

Riansyah, R. R., Nurhasanah, Y. I., Dewi, I. A., \& Belakang, A. L. (2017). Sistem Pengenalan Aksara Sunda Menggunakan Metode Modified Direction Feature Dan Learning Vector Quantization. 3(April), 17-30.

Santoso, A., \& Ariyanto, G. (2018). Implementasi Deep Learning Berbasis Keras Untuk Pengenalan Wajah. Emitor: Jurnal Teknik Elektro, 18(01), 15-21. https://doi.org/10.23917/emitor.v18i01.6235 